\title{
Homocysteine: An Emerging Cardiovascular Risk Factor that Never Really Made it
}

\author{
Vasilios G. Athyros*, ${ }^{*}$, Konstantinos Tziomalos ${ }^{2}$, Asterios Karagiannis ${ }^{1}$ and Dimitri P. Mikhailidis ${ }^{2}$ \\ ${ }^{I}$ Second Propedeutic Department of Internal Medicine, Aristotle University, Hippocration Hospital, Thessaloniki, \\ Greece \\ ${ }^{2}$ Department of Clinical Biochemistry (Vascular Prevention Clinic) and Department of Surgery, Royal Free Hospital \\ Campus, University College London Medical School, University College London (UCL), London, UK
}

\begin{abstract}
Serum total homocysteine (tHcy) has been implicated in promoting venous thromboembolic events and atherosclerosis, manifested as coronary heart disease, stroke or peripheral arterial disease. Dietary supplementation with B vitamins that lower tHcy concentrations was expected to reduce cardiovascular disease (CVD) risk. However, recent metaanalyses of prospective observational studies and randomized controlled trials failed to show a role of tHcy in the pathogenesis of vascular disease or a benefit of B vitamins in CVD events. This review analyzes recent data on the potential of tHcy to cause health problems (if any) and the role of vitamin B supplementation in preventing them.
\end{abstract}

Keywords: Homocysteine, folate, vitamin B, cystathionine beta-synthase, methylene tetrahydrofolate reductase, cardiovascular disease risk.

\section{A. INTRODUCTION}

A role of homocysteine (Hcy), a product of methionine metabolism, in the pathogenesis of coronary artery disease (CAD) was first suggested in 1969 [1], when McCully proposed that Hcy causes arterial and venous atherothrombotic disease. His hypothesis was based on rare genetic disorders associated with extremely elevated plasma total Hcy (tHcy) concentrations, homocystinuria and premature atherothrombotic disease [1]. These conditions provided a model for vascular injury associated with exposure to high tHcy concentrations. Data from observational studies, meta-analyses [29] and studies using surrogate end-points [10,11] suggested that an elevated plasma tHcy concentration promotes atherosclerosis and thrombotic vascular disease and is associated with an increased risk of myocardial infarction (MI) and stroke. The issue was whether or not tHcy is a modifiable causal risk factor for cardiovascular disease (CVD) or simply a marker of risk burden [10]. Recently, the Study of the Effectiveness of Additional Reductions in Cholesterol and Homocysteine (SEARCH), a large, long-term (7 years), prospective, randomized, double-blind, placebo-controlled trial with a 2 by 2 factorial design [12,13] and meta-analyses of smaller prospective observational studies and randomized controlled trials [14] have failed to establish a role for tHcy as a causal risk factor for atherothrombotic vascular disease. Results of SEARCH suggest that tHcy lowering does not affect the risk for vascular events and there was no benefit in

*Address correspondence to this author at the Head of Atherosclerosis and Metabolic Syndrome Units, Second Propedeutic Department of Internal Medicine, Aristotle University, Hippocration Hospital, Thessaloniki, 55 132, Greece; Tel: +30 2310454 237; Fax: +30 2310445 220;

E-mail: athyros@med.auth.gr any of the analysed subgroups $[12,13]$. Thus, tHcy does not appear to be a therapeutic target.

However, an analysis of available data on tHcy effects on clinical manifestations of atherothrombosis (if any) is necessary in order to devise pharmacological interventions accordingly or to abandon monitoring tHcy altogether.

\section{B. SEARCH METHODS}

A literature search (using PubMed) was performed using the following key words: "homocysteine", "coronary heart disease", "cardiovascular disease", "stroke", "morbidity", "mortality", "risk", "thrombosis", "venous thromboembolism", "heart failure", "peripheral arterial disease", "coronary artery bypass graft surgery" and "dementia" up to 15 March 2009. The authors also manually reviewed the references of retrieved articles for any pertinent material.

\section{PATHOPHYSIOLOGY OF THE EFFECTS OF tHcy ON ATHEROSCLEROSIS AND THROMBOSIS}

Hcy is a sulfur-containing intermediate product of the metabolism of methionine (an essential amino acid) [1]. When methionine is in excess, Hcy is directed to the transsulfuration pathway, where it is metabolized to cystathionine, thereafter to cysteine and ultimately to inorganic sulfate. The enzyme cystathionine beta-synthase (CBS) is essential in the transsulfuration pathway, as is vitamin $B_{6}$, which acts as a co-factor. However, under conditions of negative methionine balance tHcy is primarily metabolized through a methionine-conserving remethylation pathway, which involves the enzymes methionine synthase and methylene tetrahydrofolate reductase (MTHFR) and several B vitamins, namely $B_{12}$, folate (a methyl group donor), $B_{2}$ and $\mathrm{B}_{6}$ [14]. Folic acid, vitamin $\mathrm{B}_{12}$ and vitamin $\mathrm{B}_{6}$ deficiency 
and reduced enzyme activities result in decreased Hcy breakdown and increased intracellular Hcy concentration [15].

In the plasma, about $70 \%$ of Hcy is protein bound, almost $30 \%$ is bound to other Hcy or cysteine molecules to form disulfides and about $1 \%$ is present as free Hcy. tHcy reflects the combined pool of circulating Hcy and is measured in the fasting state. Post-methionine loading tHcy levels are more accurate [14]. Hyperhomocysteinemia (defined as tHcy levels $>15 \mu \mathrm{mol} / \mathrm{l})$ is common and can occur in healthy individuals but also in the presence of deficiencies of B vitamins, increased consumption of methionine-rich animal proteins, increasing age, smoking, postmenopausal state, sedentary lifestyle, decreased renal function, or with less severe genetic abnormalities of CBS or MTHFR [16,17]. Rare enzyme deficiencies such as methionine synthase deficiency or defects of cobalamin metabolism, or mutations, such as homozygocity for CBS or MTHFR can cause severe hyperhomocysteinemia (fasting plasma tHcy levels $>100 \mu \mathrm{mol} / \mathrm{l}$ ) [14].

Pro-atherogenic and pro-thrombotic effects of tHcy were believed to be mediated through adverse effects on platelet, endothelial and smooth muscle cell function, on redox balance and on methylation of genes (which alters their expression and function) [15]. The effects of tHcy on platelet function and thrombosis include stimulation of platelet thromboxane-A2, activation of factor $\mathrm{V}$ and interference with protein $\mathrm{C}$ activation, prostacyclin bioavailability and heparin sulfate expression [18-20]. Effects on endothelial and smooth muscle cell function include endothelial cell injury and inhibition of DNA synthesis in vascular endothelial cells, smooth muscle cell proliferation and intimal thickening $[21,22]$. tHcy oxidizes low density lipoprotein (LDL) particles, promotes generation of free radicals, inhibits intracellular antioxidant enzymes, reduces the bioavailability of nitric oxide (NO) and induces endothelial dysfunction [23,24]. At the genetic level, tHcy alters the methylation status of genes thus contributing to altered gene expression $[25,26]$. Elevated Hcy levels were also associated with increased arterial stiffness in hypertensive patients [27].

\section{EFFECT OF HYPERHOMOCYSTEINEMIA ON ADVERSE EVENTS AND THE POTENTIAL OF VI- TAMIN B THERAPY TO REDUCE THE RISK FOR THESE EVENTS}

\section{Venous Thromboembolism}

Epidemiological data suggest an association between tHcy and venous thromboembolism (VTE), including deep vein thrombosis and pulmonary embolism $[28,29]$. Retrospective case-control studies reported strong associations between tHcy levels and VTE. In these studies, tHcy levels were measured after the onset of the VTE events, so that it could not be established whether the high tHcy concentrations were the cause or the result of the VTE. A metaanalysis of retrospective studies reported that a $5 \mu \mathrm{mol} / 1$ higher tHcy concentration was associated with a $60 \%$ higher risk for VTE [30].

The above data suggest that elevated tHcy might be associated with a higher risk for VTE. Whether decreasing tHcy levels with vitamin B therapy reduces the risk for VTE is still unclear. A secondary analysis of the Heart Outcomes Prevention Evaluation (HOPE) 2 study (double-blind, placebo-controlled, randomized trial) addressed this question [31]. HOPE 2 included 5,522 patients, 55 years or older, with known CVD ( $83 \%$ of patients had a history of CAD) or diabetes mellitus (DM) and at least 1 other vascular risk factor. Patients were on a daily supplement of $2.5 \mathrm{mg}$ of folic acid, $50 \mathrm{mg}$ of vitamin $\mathrm{B}_{6}$, and $1 \mathrm{mg}$ of vitamin $\mathrm{B}_{12}$ or matching placebo for 5 years. The tHcy level decreased by $2.2 \mu \mathrm{mol} / 1$ in the vitamin therapy group and increased by $0.80 \mu \mathrm{mol} / 1$ in the placebo group. VTE occurred in $88 \mathrm{par}-$ ticipants during a mean follow-up of 5 years [hazard ratio (HR) 1.01 (95\% confidence interval (CI), 0.66-1.53)]. The incidence rate of VTE was the same in the vitamin therapy group and the placebo group and vitamin therapy did not reduce the risk for deep venous thrombosis, pulmonary embolism or unprovoked VTE [HR 1.04 (95\% CI, 0.63-1.72), 1.14 (95\% CI, 0.57-2.28) and 1.21 (95\% CI, 0.66-2.23), respectively]. Therefore, decreasing tHcy levels with folic acid and vitamins $\mathrm{B}_{6}$ and $\mathrm{B}_{12}$ did not reduce the risk for symptomatic VTE in this post hoc analysis of the HOPE 2 study [31]. Similarly, the Vitamins and Thrombosis (VITRO) trial [32], conducted in 701 patients after a first episode of unprovoked deep vein thrombosis or pulmonary embolism (secondary prevention of VTE), found no convincing benefit for B vitamin therapy in preventing recurrent VTE events. In summary, the results of prospective randomized controlled trials have failed to demonstrate conclusive benefits for tHcy-lowering vitamin B therapy in the prevention of first or recurrent VTE or pulmonary embolism.

\section{Cardiovascular Disease}

A common polymorphism of the gene encoding for the MTHFR enzyme is the MTHFR $677 \mathrm{C} \rightarrow \mathrm{T}$ gene variant. Homozygosity for the variant allele, the TT genotype, which is observed in about $10 \%$ in most ethnic groups, leads to $25 \%$ higher tHcy concentrations than in individuals with the common CC genotype [14]. It is important to emphasize, however, that folate levels modulate the effect of this polymorphism on CVD risk. Associations between this polymorphism and CVD risk should not be subject to reverse causality and should also be largely independent from confounding by other CVD risk factors.

\section{a. Observational Studies and their Meta-Analyses}

A large number of observational studies evaluated the association between the TT genotype and CAD or stroke with conflicting results $[4,16,17,33]$. A large meta-analysis of 26,000 cases and 31,183 controls [33] found a weak association of tHcy levels and CAD [odds ratio (OR) 1.14; 95\% CI, 1.05-1.24] for the TT versus the CC genotype [34]. The heterogeneity of the studies analysed, mainly due to a very wide global distribution of cohorts with deferent degrees of folate intake, might have affected the results of this metaanalysis. Another meta-analysis [6] comprising 6,324 cases and 7,604 controls reported a possible causal link between Hcy and stroke (OR 1.26; 95\% CI, 1.14-1.40 for the TT versus the CC genotype). In a recent study in the general Chinese population, elevated Hcy levels were associated with increased risk for CAD events and all-cause mortality but not with the risk for stroke [35]. In contrast, elevated Hcy levels were associated with increased risk for stroke recur- 
rence and all-cause mortality in Chinese stroke survivors [36].

\section{b. Surrogate Endpoints}

In a prospective, randomized, placebo-controlled trial, including 103 patients with at least one CVD risk factor, supplementation of folic acid (5 mg/day for 18 months) reduced carotid intima media thickness (cIMT) [11]. In contrast, another prospective, randomized, placebo-controlled study showed that short-term treatment with B vitamins was associated with increased flow-mediated dilation (FMD) but long-term tHcy-lowering did not significantly improve FMD or cIMT in patients with a history of stroke [10]. Thus, the effects of tHcy lowering on surrogate end-points are also conflicting.

\section{c. Inflammatory Markers}

tHcy-lowering might affect subclinical inflammation, which is related to atherosclerosis $[37,38]$. In a recent study [39] in patients with stable CAD, tHcy-lowering therapy with folate, B12 and B6 did not affect circulating levels of inflammatory markers [C-reactive protein (CRP) or soluble CD40 ligand].

\section{d. Prospective, Randomized, Clinical Endpoint Trials}

The Norwegian Vitamin (NORVIT) Trial evaluated the efficacy of tHcy-lowering treatment with B vitamins for secondary prevention of CVD in 3,749 men and women who had had an acute MI within 7 days before randomization [40]. Patients were randomly assigned, in a 2 by 2 factorial design, to receive one of 4 daily treatments: $0.8 \mathrm{mg}$ of folic acid, $0.4 \mathrm{mg}$ of vitamin $\mathrm{B}_{12}$ and $40 \mathrm{mg}$ of vitamin $\mathrm{B}_{6} ; 0.8 \mathrm{mg}$ of folic acid and $0.4 \mathrm{mg}$ of vitamin $\mathrm{B}_{12} ; 40 \mathrm{mg}$ of vitamin $\mathrm{B}_{6}$; or placebo. The primary end point was a composite of recurrent MI, stroke and sudden death attributed to CAD [40]. After a median follow-up of 40 months, mean tHcy levels were lowered by $27 \%$ among patients given folic acid plus vitamin $B_{12}$ but such treatment had no significant effect on the primary end point [relative risk (RR) 1.08; 95\% CI, 0.93 $1.25 ; \mathrm{p}=0.31]$. Also, treatment with vitamin $\mathrm{B}_{6}$ was not associated with any significant benefit (RR 1.14; 95\% CI, $0.98-1.32 ; p=0.09)$. In the group given folic acid, vitamin $\mathrm{B}_{12}$ and vitamin $\mathrm{B}_{6}$, there was a trend toward an increased risk (RR 1.22; 95\% CI, 0.98-1.32; p = 0.05) [40]. Results of the NORVIT trial suggest that treatment with $\mathrm{B}$ vitamins does not lower the risk of recurrent CVD after acute MI, and that combined B vitamin treatment might be associated with a harmful effect [40].

Another analysis of the HOPE 2 Trial was published in 2006 [41]. In this study, despite tHcy lowering by 2.4 $\mu \mathrm{mol} / \mathrm{l}$, there was no effect on the primary outcome (a composite of CVD death, MI and stroke) [41]. In contrast, there was a significant increase in the risk for hospitalization for unstable angina by $24 \%$ (95\% CI, 1.04-1.49; p = 0.02). However, the risk for stroke was significantly reduced by 25\% (95\% CI, 0.59-0.97; p = 0.03) [41].

The Vitamin Intervention for Stroke Prevention (VISP), a randomized controlled trial, was designed to determine whether high doses of folic acid, $\mathrm{B}_{6}$ and $\mathrm{B}_{12}$, given to lower tHcy levels, reduce the risk of recurrent stroke over a 2-year period compared with low doses of these vitamins [42]. 3,680 patients with non-disabling cerebral infarction were enrolled at 56 university-affiliated hospitals, community hospitals, private neurology practices and Veterans Affairs medical centers in the United States, Canada and Scotland. This trial showed that a moderate difference of tHcy levels between the 2 treatment groups $(2 \mu \mathrm{mol} / \mathrm{l})$ had no effect on vascular outcomes [42].

In the SEARCH trial, 12,064 MI survivors were randomized to either $20 \mathrm{mg}$ or $80 \mathrm{mg}$ of simvastatin daily for the more vs less LDL-lowering comparison and to folic acid 2 mg plus vitamin $B_{12} 1 \mathrm{mg} /$ day or placebo for the tHcylowering comparison for a total of 7 years $[12,13]$. The primary end point was a composite of major coronary events, stroke and revascularization. For the higher vs lower statin dose comparison, there was a $14 \%$ further reduction in LDL cholesterol levels $[0.35 \mathrm{mmol} / 1(14 \mathrm{mg} / \mathrm{dl})]$ in the intensive arm compared with the $20 \mathrm{mg}$ arm. However, there was no difference in the primary end point between the groups: 1,477 events $(24.5 \%)$ in the $80 \mathrm{mg}$ simvastatin group vs 1,553 events $(25.7 \%)$ in the lower-dose group $(\mathrm{p}=0.10)$ $[12,13]$. In the tHcy-lowering arm of SEARCH, there were 1,537 major vascular events in the folic acid/vitamin $B_{12}$ arm vs 1,493 in the placebo arm (risk ratio 1.04) $[12,13]$. The results of the SEARCH trial suggest that tHcy lowering does not affect the risk of vascular events and this was observed in all analysed subgroups $[12,13]$. Thus, the results of this large, prospective, randomized, placebo-controlled, longterm trial (7 years) suggests that tHcy lowering is not beneficial for preventing CVD.

A possible exception might be CAD patients with endstage renal disease, in whom it seems that high tHcy is associated with increased CAD mortality. In this population, there was a $3 \%$ increase in CAD mortality with each increase of $1 \mu \mathrm{mol} / \mathrm{L}$ of tHcy [43]. This is in agreement with previous findings showing an association between tHcy and CVD risk factors in uremic patients [44]. However, CAD patients with end-stage renal disease are a very different category of high risk patients.

\section{Congestive Heart Failure}

Recently, tHcy has been reported to be increased in congestive heart failure (CHF) patients with or without CAD, potentially representing a risk marker or risk factor $[45,46]$. It was shown that high tHcy levels are associated with left ventricular (LV) dysfunction [47]. This relationship was independent of CHF etiology and gender. Further research is indicated to distinguish between a causal or noncausal mechanism for this association. In the Multi-Ethnic Study of Atherosclerosis (MESA), magnetic resonance imaging studies in 1,178 asymptomatic participants without CAD were used to assess regional LV function [48]. The fully adjusted model (considering traditional risk factors, race, height, weight, LV end-diastolic mass/volume, serum creatinine and measures of atherosclerosis) showed an association between elevated tHcy and increased risk for reduced regional LV systolic function in the left anterior descending area (HR $1.33 ; 95 \%$ CI, 1.04-1.70; $\mathrm{p}<0.022)$, the left circumflex area (HR 1.28; 95\% CI, 1.00-1.64; p < 0.046) and the right coronary artery area (HR 1.32; 95\% CI, 1.03-1.69; p < 0.025) [48]. Mechanistic studies of the role of hyperhomocysteinemia in $\mathrm{CHF}$ are rare. However, preliminary results suggest that hyperhomocysteinemia causes adverse cardiac remodel- 
ling characterized by interstitial and perivascular fibrosis resulting in increased myocardial stiffness. In addition, hyperhomocysteinemia seems to adversely affect myocardial contractility $[49,50]$. The mechanisms leading from an elevated thcy level to reduced myocardial contractility and adverse cardiac remodelling are a matter of speculation. Existing data indicate that direct effects of tHcy on the myocardium as well as NO-independent vascular effects are involved [49,50]. Preliminary data from small intervention trials suggested that tHcy lowering might improve clinical and laboratory markers of CHF [50]. Nevertheless, larger intervention trials are needed to clarify whether modification of plasma tHcy by B vitamin supplementation improves the clinical outcome in CHF patients [50].

\section{Post-Cardiac Surgery}

Patients undergoing cardiac surgery are at significant risk for serious adverse events, including MI, unstable angina, stroke, mesenteric ischemia, deep vein thrombosis and pulmonary embolism. These result in relatively high operative and post-operative morbidity and mortality [51,52]. There appears to be a relationship between pre-operative tHcy levels and short-term (30-day) [53] and long-term (2-years) [54] postoperative CVD events in this high-risk group of CAD patients.

A recent prospective study in 531 consecutive patients undergoing cardiac operations [mainly coronary artery bypass graft surgery (CABG)] evaluated the association between pre-operative plasma tHcy levels with post-operative morbidity and hospital mortality [53]. Elevated tHcy levels $(>15 \mu \mathrm{mol} / \mathrm{l})$ were observed in 209 patients $(39.4 \%)$ and hyperhomocysteinemia was associated with a higher mortality and peri-operative major morbidity (low cardiac output, acute renal failure, mesenteric infarction and thromboembolic events). In another prospective study (121 CAD patients undergoing $\mathrm{CABG}$ ), preoperative tHcy levels were significantly related to the combined end point of death, nonfatal MI and bypass graft disease during a 2-year follow-up [54].

There are also genetic data on CAD patients undergoing CABG (MTHFR or C677 gene variants). In the genetic substudy of the Medicine, Angioplasty or Surgery Study (MASS) II [55], a significant $(\mathrm{p}=0.007)$ association between the MTHFR TT genotype and CVD mortality was observed during a 5-year follow-up. This association was significant (a 4.4 fold increased risk for CVD outcomes; $p=$ 0.01 ) after adjustment for age, sex, hypertension, DM, LDL cholesterol, high density lipoprotein cholesterol, triglycerides and number of diseased vessels. In addition, there appears to be a dynamic regulation of MTHFR gene expression during the arterialization process of human saphenous vein grafts [56]. Moreover, the C677T MTHFR functional variant was associated with a worse outcome in patients undergoing CABG. Taken together, these data suggest a role for tHcy in CABG [56]. Another study assessed the relationship between tHcy levels and mortality after CABG surgery in 350 patients prospectively followed for 58 months [57]. After adjustment for statin therapy, high sensitivity CRP levels, as well as genetic (MTHFR 677C $\rightarrow$ T polymorphism) and non-genetic tHcy determinants (B vitamin status and renal function), tHcy was independently associated with mortality (HR 5.02, 95\% CI, 1.88-13.42, p = 0.001) [57].

\section{Peripheral Arterial Disease}

Patients with peripheral arterial disease (PAD) have increased mortality from CVD events compared with age- and sex-matched controls $[58,59]$. Platelets play a major role in atherothrombotic vascular events and platelet reactivity is increased in patients with PAD compared with healthy controls [59]. tHcy appears to be implicated in endothelial dysfunction and haemostatic abnormalities [14]. It has been shown that the presence of claudication alone does not influence platelet function but if mild hyperhomocysteinemia is also present, platelet sensitivity to agonists is increased and their sensitivity to inhibition is reduced [60]. The overall effect would be an increased propensity for platelet activation. Thus, the presence of even mildly elevated plasma tHcy in claudicants might increase thrombotic risk [60]. In subjects with homozygous homocystinuria (where plasma tHcy levels are 100-200 $\mu \mathrm{mol} / \mathrm{l})$, increased circulating levels of thromboxane B2 are observed and are reduced with aspirin $[61,62]$. These findings suggest that higher plasma tHcy levels may lead to increased platelet activity in vivo $[61,62]$.

\section{Dementia}

High tHcy concentrations appear to be associated with a greater risk for dementia and cognitive impairment without dementia (CIND), related or not to vascular impairment, as well as with Alzheimer's disease (AD) [63]. Some cohort studies suggested a relationship between elevated tHcy concentrations and a greater risk for $\mathrm{AD}$ or dementia $[64,65]$ whereas others did not find an association [66]. A prospective study (1,779 subjects, $60-101$ years old, primarily Mexican American Latinos who were residing in the Sacramento Valley of California from 1997 to 1999) was undertaken to evaluate the association between baseline plasma tHcy and the 4.5-year combined incidence of dementia and CIND [63]. tHcy was associated with a greater risk for dementia or CIND independently of red blood cell folate concentration. The association of tHcy and dementia or CIND might be modified by plasma vitamin $B_{12}$ levels [63]. It is unclear whether low vitamin $\mathrm{B}_{12}$ or folate status was responsible for the greater risk of dementia or cognitive decline associated with elevated serum tHcy concentrations in these studies. It is also unclear if $B_{12}$ or folate supplementation might have beneficial effects on dementia independently of tHcy reduction [67].

\section{E. CONCLUSIONS}

Current evidence suggests that elevated tHcy levels are not an independent CVD risk factor and that there is no need for routine measurement of tHcy levels. Some rare genetic disorders related to very high tHcy levels $(>100 \mu \mathrm{mol} / \mathrm{l})$ might justify vitamin B supplementation. However, in primary and secondary CAD disease prevention routine vitamin B supplementation might prove to be dangerous, as observed in the NORVIT [40] and HOPE 2 studies [41].

\section{DECLARATION OF INTEREST}

This review was written independently; no company or institution supported it financially. Some of the authors at- 
tended conferences, given lectures and participated in advisory boards or other trials sponsored by various pharmaceutical companies.

\section{REFERENCES}

[1] McCully, K.S. Vascular pathology of homocystinemia: implications for the pathogenesis of arteriosclerosis. Am. J. Pathol., 1969, 56(1), 111-128.

[2] Boushey, C.J.; Beresford, S.A.; Omenn, G.S.; Motulsky, A.G. A quantitative assessment of plasma homocysteine as a risk factor for vascular disease. Probable benefits of increasing folic acid intakes. JAMA, 1995, 274(13), 1049-1057.

[3] Hankey, G.J.; Eikelboom, J.W. Homocysteine and vascular disease. Lancet, 1999, 354(9176), 407-413.

[4] Wald, D.S.; Law, M.; Morris, J.K. Homocysteine and cardiovascular disease: evidence on causality from a meta-analysis. BMJ, 2002, 325(7374), 1202 .

[5] The Homocysteine Studies Collaboration. Homocysteine and risk of ischemic heart disease and stroke: a meta-analysis. JAMA, 2002, 288(16), 2015-2022.

[6] Casas, J.P.; Bautista, L.E.; Smeeth, L.; Sharma, P.; Hingorani, A.D. Homocysteine and stroke: evidence on a causal link from Mendelian randomisation. Lancet, 2005, 365(9455), 224-232.

[7] Perry, I.J.; Refsum, H.; Morris, R.W.; Ebrahim, S.B.; Ueland, P.M.; Shaper, A.G. Prospective study of serum total homocysteine concentration and risk of stroke in middle-aged British men. Lancet, 1995, 346(8987), 1395-1398.

[8] Stubbs, P.J.; Al-Obaidi, M.K.; Conroy, R.M.; Collinson, P.O.; Graham, I.M.; Noble, M.I.M. Effect of plasma homocysteine concentration on early and late events in patients with acute coronary syndromes. Circulation, 2000, 102(6), 605-610.

[9] Bostom, A.G.; Silbershatz, H.; Rosenberg, I.H.; Jacques, P.F.; Selhub, J.; D'Agostino, R.B.; Wilson, P.W.; Wolf, P.A. Nonfasting plasma total homocysteine levels and all-cause and cardiovascular disease mortality in elderly Framingham men and women. Arch. Intern. Med., 1999, 159(10), 1077-1080.

[10] Potter, K.; Hankey, G.J.; Green, D.J.; Eikelboom, J.; Jamrozik, K.; Arnolda, L.F. The effect of long-term homocysteine-lowering on carotid intima-media thickness and flow-mediated vasodilation in stroke patients: a randomized controlled trial and meta-analysis. BMC Cardiovasc. Dis., 2008, 8, 24.

[11] Ntaios, G.; Savopoulos, C.; Karamitsos, D.; Economou, I.; Destanis, E.; Chryssogonidis, I.; Pidonia, I.; Zebekakis, P.; Polatides, C.; Sion, M.; Grekas, D.; Hatzitolios, A. The effect of folic acid supplementation on carotid intima-media thickness in patients with cardiovascular risk: A randomized, placebo-controlled trial. Int. J. Cardiol., 2009. (E-pub ahead of print).

[12] SEARCH Study Collaborative Group. Study of the effectiveness of additional reductions in cholesterol and homocysteine (SEARCH): Characteristics of a randomized trial among 12064 myocardial infarction survivors. Am. Heart. J., 2007, 154(5), 815-823.

[13] SEARCH Study Collaborative Group. Study of the effectiveness of additional reductions in cholesterol and homocysteine (SEARCH): folic acid plus vitamin B12 or placebo for the evaluation of homocysteine-lowering on clinical outcome. American Heart Association Sienetific Session, Late-breaking Clinical Trial Session, New Orleans, Louisiana, 9 Nov 2008. (Abstract)

[14] Lonn, E. Homocysteine in the prevention of ischemic heart disease, stroke and venous thromboembolism: therapeutic target or just another distraction? Curr. Opin. Hematol., 2007, 14(5), 481-487.

[15] Mallika, V.; Goswami, B.; Rajappa, M. Atherosclerosis Pathophysiology and the Role of Novel Risk Factors: A Clinicobiochemical Perspective. Angiology, 2007, 58(5), 513-522.

[16] Kaul, S.; Zadeh, A.A.; Shah, P.K. Homocysteine hypothesis for atherothrombotic cardiovascular disease: not validated. J. Am. Coll. Cardiol., 2006, 48(5), 914-923.

[17] Eikelboom, J.W.; Lonn, E.; Genest, J.; Hankey, G.; Yusuf, S. Homocyst(e)ine and cardiovascular disease: a critical review of the epidemiologic evidence. Ann. Intern. Med., 1999, 131(5), 363-375.

[18] Harpel, P.C.; Chang, V.T.; Borth, W. Homocysteine and other sulfhydryl compounds enhance the binding of lipoprotein (a) to fibrin. A potential biochemical link between thrombosis, atherogenesis and sulfhydryl compound metabolism. Proc. Natl. Acad. Sci. USA, 1992, 89(21), 10193-10197.
[19] Lentz, S.R.; Sadler, J.E. Inhibition of thrombomodulin surface expression and protein $\mathrm{C}$ activation by the thrombogenic agent homocysteine. J. Clin. Invest., 1991, 88(6), 1906-1914.

[20] Nishinaga, M.; Ozawa, T.; Shimado, K. Homocysteine, a thrombogenic agent, suppresses anticoagulant heparin sulphate expression in cultured porcine aortic endothelial cells. J. Clin. Invest., 1993, 92(3), 1381-1386.

[21] Wall, R.; Harlan, J.M.; Harker, L.A.; Striker, G.E. Homocysteine induced endothelial cell injury in vivo: a review. Thromb. Res., 1980, 18(1-2), 113-121.

[22] Dudman, N.P.B.; Temple, S.E.; Guo, X.W.; Fu, W.Y.; Perry, M.A. Homocysteine enhances neutrophil endothelial interactions in vivo. Circ. Res., 1999, 84(4), 409-416.

[23] Heinecke, J.W.; Rosen, H.; Suzuki, L.A.; Chait, A. The role of sulphur containing amino acids in super oxide production and modification of low density lipoprotein in arterial smooth muscle cells. J. Biol. Chem., 1987, 262(21), 10098-10103.

[24] Upchurch, G.R.; Welch, G.N.; Fabian, A.J. Homocysteine decreases bioavailable nitric oxide by a mechanism involving glutathione peroxidase. J. Biol. Chem., 1997, 272(27), 17012-17017.

[25] Hiltunen, M.O.; via-Herttual, S. DNA methylation, smooth muscle cells, and atherogenesis. Arterioscler. Thromb. Vasc. Biol., 2003, 23(10), 1750-1753.

[26] Krumkan, I.I.; Culmsee, C.; Chan, S.L.; Kruman, Y.; Guo, Z.; Penix, L.; Mattson, M.P. Homocysteine elicits a DNA damage response in neurons that promotes apoptosis and hypersensitivity to excitotoxins. J. Neurosci., 2000, 20(18), 6920-6926.

[27] Vyssoulis, G.; Karpanou, E.; Kyvelou, S.M.; Adamopoulos, D.; Gialernios, T.; Gymnopoulou, E.; Cokkinos, D.; Stefanadis C. Associations between plasma homocysteine levels, aortic stiffness and wave reflection in patients with arterial hypertension, isolated office hypertension and normotensive controls. J. Hum. Hypertens., 2009 [Epub ahead of print].

[28] Ray, J.G. A meta-analysis of hyperhomocyst(e)inemia and the risk of venous thromboembolic disease. Arch. Intern. Med., 1998, 158(19), 2101-2106.

[29] Eichinger, S.; Stumpflen, A.; Hirschl, M.; Bialonczyk, C.; Herkner, K.; Stain, M.; Schneider, B.; Pabinger, I.; Lechner, K.; Kyrle, P.A. Hyperhomocysteinemia is a risk factor of recurrent venous thromboembolism. Thromb. Haemost., 1998, 80(4), 566-569.

[30] den Heijer, M.; Lewington, S.; Clarke, E. Homocysteine, MTHFR and risk of venous thrombosis: a meta-analysis of published epidemiological studies. J. Thromb. Haemost., 2005, 3(2), 292-299.

[31] Ray, J.G.; Kearon, C.; Yi, Q.; Sheridan, P.; Lonn, E.; for the Heart Outcomes Prevention Evaluation 2 (HOPE-2) Investigators. Homocysteine-lowering therapy and risk for venous thromboembolism: a randomized trial. Ann. Intern. Med., 2007, 146(11), 761767.

[32] den Heijer, M.; Willems, H.P.J.; Blom, H.J.; Gerrits, W.B.; Cattaneo, M.; Eichinger, S.; Rosendaal, F.R.; Bos, G.M. Homocysteine lowering by B vitamins and the secondary prevention of deep vein thrombosis and pulmonary embolism: a randomized, placebocontrolled, double-blind trial. Blood, 2007, 109(1), 139-144.

[33] Klerk, M.; Verhoef, P.; Clarke, R.; Blom, H.J.; Kok, F.J., Schouten, E.G. MTHFR Studies Collaboration Group MTHFR 677C-T polymorphism and risk of coronary heart disease: a meta-analysis. JAMA, 2002, 288(16), 2023-2031.

[34] Lewis, S.J.; Ebrahim, S.; Smith, G.D. Meta-analysis of MTHFR 677C-T polymorphism and coronary heart disease: does totality of evidence support causal role for homocysteine and preventive potential of folate? BMJ, 2005, 331(7524), 1053-1058.

[35] Sun,Y.; Chien, K.L.; Hsu, H.C.; Su, T.C.; Chen, M.F.; Lee, Y.T. Use of serum homocysteine to predict stroke, coronary heart disease and death in ethnic Chinese. Circ. J., 2009 [Epub ahead of print].

[36] Zhang, W.; Sun, K.; Chen, J.; Liao, Y.; Qin, Q.; Ma, A.; Wang, D.; Zhu, Z.; Wang, Y.; Hui, R. High plasma homocysteine levels contribute to the risk of stroke recurrence and all-cause mortality in a large prospective stroke population. Clin. Sci. (Lond), 2009 [Epub ahead of print].

[37] Ross, R. Atherosclerosis: an inflammatory disease. N. Engl. J. Med., 1999, 340(2), 115-126.

[38] Athyros, V.G.; Kakafika, A.I.; Karagiannis, A.; Mikhailidis, D.P. Do we need to consider inflammatory markers when we treat atherosclerotic disease? Atherosclerosis, 2008, 200(1), 1-12. 
[39] Bleie, O.; Semb, A.G.; Grundt, H.; Nordrehaug, J.E.; Vollset, S.E.; Ueland, P.M.; Nilsen, D.W.T.; Bakken, A.M.; Refsum, H.; Nyga, O.K. Homocysteine-lowering therapy does not affect inflammatory markers of atherosclerosis in patients with stable coronary artery disease. J. Intern. Med., 2007, 262(2), 244-253.

[40] Bonaa, K.H.; Njolstad, I.; Ueland, P.M.; Schirmer, H.; Tverdal, A.; Steigen, T.; Wang, H.; Nordrehaug, J.E.; Arnesen, E.; Rasmussen, $\mathrm{K}$. For the NORVIT Trial Investigators. Homocysteine lowering and cardiovascular events after acute myocardial infarction. $N$. Engl. J. Med., 2006, 354(15), 1578-1588.

[41] Lonn, E.; Yusuf, S.; Arnold, M.J.; Sheridan, P.; Pogue, J.; Micks, M.; McQueen, M.J.; Probstfield, J.; Fodor, G.; Held, C.; Genest, J. Heart Outcomes Prevention Evaluation (HOPE) 2 Investigators: homocysteine lowering with folic acid and B vitamins in vascular disease. N. Engl. J. Med., 2006, 354(15), 1567-1577.

[42] Toole, J.F.; Malinow, M.R.; Chambless, L.E.; Spence, J.D.; Pettigrew, L.C.; Howard, V.J.; Sides, E.G.; Wang, C.H.; Stampfer, M. Lowering homocysteine in patients with ischemic stroke to prevent recurrent stroke, myocardial infarction, and death: the Vitamin Intervention for Stroke Prevention (VISP) randomized controlled trial. JAMA, 2004, 291(5), 565-575.

[43] Buccianti, G.; Baragetti, I.; Bamonti, F.; Furiani, S.; Dorighet, V.; Patrosso, C. Plasma homocysteine levels and cardiovascular mortality in patients with end-stage renal disease. J. Nephrol., 2004, 17(3), 405-410.

[44] Vianna, A.C.; Mocelin, A.J.; Matsuo, T.; Morais-Filho, D.; Largura, A.; Delfino, V.A.; Soares, A.E.; Matni, A.M. Uremic hyperhomocysteinemia: a randomized trial of folate treatment for the prevention of cardiovascular events. Hemodial. Int., 2007, 11(2), 210-216.

[45] Vasan, R.S., Beiser, A.; D'Agostino, R.B.; Levy, D.; Selhub, J.; Jacques, P.F.; Rosenberg, I.H.; Wilson, P.W. Plasma homocysteine and risk for congestive heart failure in adults without prior myocardial infarction. JAMA, 2003, 289(10), 1251-1257.

[46] Ventura, P.; Panini, R.; Verlato, C.; Scarpetta, G.; Salvioli G. Hyperhomocysteinemia and related factors in 600 hospitalized elderly subjects. Metabolism, 2001, 50(12), 1466-1471.

[47] May, H.T.; Alharethi, R.; Anderson, J.L.; Muhlestein, J.B.; Reyna, S.P.; Bair, T.L.; Horne, B.D.; Kfoury, A.G.; Carlquist, J.F.; Renlund, D.G. Homocysteine levels are associated with increased risk of congestive heart failure in patients with and without coronary artery disease. Cardiology, 2007, 107(3), 178-184.

[48] Nasir, K.; Tsai, M.; Rosen, B.D.; Fernandes, V.; Bluemke, D.A.; Folsom, A.R.; Lima, J.A.C. Elevated homocysteine is associated with reduced regional left ventricular function. The Multi-Ethnic Study of Atherosclerosis. Circulation, 2007, 115(2), 180-187.

[49] Herrmann, M.; Taban-Shomal, O.; Hübner, U.; Böhm, M.; Herrmann, W. A review of homocysteine and heart failure. Eur. J. Heart. Fail., 2006, 8(6), 571-576.

[50] Enrico, V.; Ivano, B.; Gregoriana, Z.; Silvia, F.; Claudia, F.; Riccardo, R.; Livio, D.C. Homocysteine and heart failure: an overview. Recent. Pat. Cardiovasc. Drug. Discov., 2009, 4(1), 15-21.

[51] The PREVENT IV Investigators. Efficacy and safety of edifoligide, an E2F transcription factor decoy, for prevention of vein graft failure following coronary artery bypass graft surgery-PREVENT IV: a randomized controlled trial. JAMA, 2005, 294(19), 2446-2454.

[52] Anyanwu, A.C.; Filsoufi, F.; Salzberg, S.P.; Bronster, D.J.; Adams, D.H. Epidemiology of stroke after cardiac surgery in the current era. J. Thorac. Cardiovasc. Surg., 2007, 134(5), 1121-1127.

[53] Shammas, N.W.; Dippel, E.J.; Jerin, M.; Toth, P.P.; Kapalis, M.; Reddy, M.; Harb, H. Elevated levels of homocysteine predict cardiovascular death, nonfatal myocardial infarction, and symptomatic bypass graft disease at 2-year follow-up following coronary artery bypass surgery. Prev. Cardiol., 2008, 11 (2), 95-99.

[54] Ranucci, M.; Ballotta, A.; Frigiola, A.; Boncilli, A.; Brozzi, S.; Costa, E.; Mehta, R.H. Pre-operative homocysteine levels and morbidity and mortality following cardiac surgery. Eur. Heart. J., 2009. (E-pub ahead of print).

[55] Pereira, A.C.; Lopes, N.H.; Soares, P.R.; Krieger, J.E.; de Oliveira, S.A.; Cesar, L.A.; Ramires, J.A.; Hueb, W. Clinical judgment and treatment options in stable multivessel coronary artery disease: results from the one-year follow-up of the MASS II (Medicine, Angioplasty, or Surgery Study II). J. Am. Coll. Cardiol., 2006, 48(5), 948-953.

[56] Pereira, A.C.; Miyakawa, A.A.; Lopes, N.H.; Soares, P.R.; de Oliveira, S.A.; Cesar, L.A.; Ramires, J.F.; Hueb, W.; Krieger, J.E. Dynamic regulation of MTHFR mRNA expression and C677T genotype modulate mortality in coronary artery disease patients after revascularization. Thromb. Res., 2007, 121(1), 25-32.

[57] Girelli, D.; Martinelli, N.; Olivieri, O.; Pizzolo, F.; Friso, S.; Faccini, G.; Bozzini, C.; Tenuti, I.; Lotto, V.; Villa, G.; Guarini, P.; Trabetti, E.; Pignatti, P.F.; Mazzucco, A.; Corrocher, R. Hyperhomocysteinemia and mortality after coronary artery bypass grafting. PLOS ONE, 2006, 1, 83-90.

[58] Taylor, L.M.; Moneta, G.L.; Sexton, G.J.; Schuff, R.A.; Porter, J.M. Prospective blinded study of the relationship between plasma homocysteine and progression of symptomatic peripheral arterial disease. J. Vasc. Surg., 1999, 29(1), 8-19.

[59] Rajagopalan, S.; Mckay, I.; Ford, I.; Bachoo, P.; Greaves, M.; Brittenden, J. Platelet activation increases with the severity of peripheral arterial disease: implications for clinical management. $J$. Vasc. Surg., 2007, 46(3), 485-590.

[60] Riba, R.; Nicolaou, A.; Troxler, M.; Homer-Vaniasinkam, S.; Naseem, K.M. Altered platelet reactivity in peripheral vascular disease complicated with elevated plasma homocysteine levels. Atherosclerosis, 2004, 175(1), 69-75.

[61] Di Minno, G.; Davi, G.; Margaglione, M.; Cirillo, F.; Grandone, E.; Ciabattoni, G.; Catalano, I.; Strisciuglio, P.; Andria, G.; Patrono, C. Abnormally high thromboxane biosynthesis in homozygous homocystinuria: evidence for platelet involvement and a probucolsensitive mechanism. J. Clin. Invest., 1993, 92(3), 1400-1406.

[62] Davi, G.; Di Minno, G.; Coppola, A.; Andria, G.; Cerbone, A.M.; Madonna, P.; Tufano, A.; Falco, A.; Marchesani, P.; Ciabattoni, G.; Patrono, C. Oxidative stress and platelet activation in homozygous homocystinuria. Circulation, 2001, 104(10), 1124-1128.

[63] Haan, M.N.; Miller, J.W.; Aiello, A.E.; Whitmer, R.A.; Jagust, W.J.; Mungas, D.M.; Allen, L.H.; Green, R. Homocysteine, B vitamins, and the incidence of dementia and cognitive impairment: results from the Sacramento Area Latino Study on Aging. Am. $J$. Clin. Nutr., 2007, 85(2), 511-517.

[64] Seshadri, S.; Beiser, A.; Selhub, J.; Jacques, P.F.; Rosenberg, I.H.; D'Agostino, R.B.; Wilson, P.W.; Wolf, P.A. Plasma homocysteine as a risk factor for dementia and Alzheimer's disease. $N$. Engl. $J$. Med., 2002, 346(7), 476-483.

[65] Ravaglia, G.; Forti, P.; Maioli, F.; Martelli, M.; Servadei, L.; Brunetti, N.; Porcellini, E.; Licastro, F. Homocysteine and folate as risk factors for dementia and Alzheimer disease. Am. J. Clin. Nutr., 2005, 82(3), 636-643.

[66] Luchsinger, J.A.; Tang, M.X.; Shea, S.; Miller, J.; Green, R.; Mayeux, R. Plasma homocysteine levels and risk of Alzheimer disease. Neurology, 2004, 62(11), 1972-1976.

[67] Tangney, C.C.; Tang, Y.; Evans, D.A.; Morris, M.C. Biochemical indicators of vitamin B12 and folate insufficiency and cognitive decline. Neurology, 2009, 72(4), 361-367. 